\title{
Dynamic analysis of metro rail bridge subjected to moving loads considering soil-structure interaction
}

\author{
Hitesh Bhure ${ }^{1} \cdot$ Gayatri Sidh $^{1} \cdot$ Anand Gharad $^{1}$ \\ Received: 22 August 2017 / Accepted: 22 August 2018 / Published online: 31 August 2018 \\ (c) The Author(s) 2018
}

\begin{abstract}
This paper investigates the dynamic response of a metro rail over-bridge, subjected to moving loads. Track irregularity and train inertia effects are not considered. Bridge superstructure, piers and substructure are modelled using shell element, rails are modelled with frame elements and the interaction between bridge deck and piers is simulated using link supports (bearings) in SAP2000 (2014). Moving load analysis is performed for two models namely fixed base model and complete pile model. For complete pile model, the piles are modelled using frame elements. IS 2911: 2010 is considered to evaluate the soil stiffness properties. Modal damping ratio of 5\% is adopted. Finite element method is used to perform the dynamic analysis and Newmark- $\beta$ method is considered to solve the equations of motion. From the comparative study between two models, and for two loading cases, it was noted that the speed of the train is a very important parameter influencing the dynamic response of the bridge. Moreover, the resonance phenomenon for the complete pile model was observed at lower speed compared to the fixed base model for both the loading cases. From this study, it can be stated that a full three-dimensional (3D) multi-span simply supported bridges' dynamic analysis is important to obtain the transient response of the bridge structure.
\end{abstract}

Keywords Soil-structure interaction $\cdot$ Resonance $\cdot$ Dynamic analysis $\cdot$ Complete pile model $\cdot$ Newmark- $\beta$

\section{Introduction}

The development of high-speed railways in various countries has increased the interest in dynamic behaviour of railway bridges. Under the loads of high speed, the bridges are subjected to high impacts. The dynamic aspects are of special interest and have often shown to be the governing factor in the structural design. Vehicle speed is an important parameter which influences the dynamic behaviour of bridge. In addition to vehicle speed, the characteristics of the bridge structure and the vehicle, the rail surface unevenness, varying vehicular travel lanes are the different parameters that govern the dynamic behaviour of bridge.

Hitesh Bhure

hitesh.bhure8@gmail.com

Gayatri Sidh

gayatri.sidh@gmail.com

Anand Gharad

gharadam@rknec.edu

1 Department of Civil Engineering, Shri Ramdeobaba College of Engineering and Management, Nagpur, India
Wang et al. (2007) investigated the resonance response of a multi-span continuous beam and simply supported beam under the action of load moving at constant velocities. Ju and Lin (2003) have provided solution to reduce the resonance phenomenon of a simply supported bridge by studying three-dimensional (3D) vehicle-bridge interaction (VBI) analysis. Fryba (2001) investigated an elementary theoretical model of a bridge using the integral transformation method. The analysis gives the critical speed at which the resonance vibration may occur. Zhang et al. (2010) studied a numerical solution for the dynamic response of a train bridge interaction subjected to multi-support seismic loads. Salcher and Adam (2012) have presented the results of a numerical study which aimed at a quick and accurate assessment of the dynamic railway bridge response subjected to high-speed trains. Li et al. (2013) have studied two different bridge models which were considered as simplified smallscale models. These models showed fair agreement with the experimental study.

Romero et al. (2013) have put in a lot to understand and explain dynamic soil-bridge interaction under high-speed train. The parametric study conducted for various types of soils resulted in concluding the fact that the resonance 
response is attained at lower speeds for loose soils. Tavares (2007) has studied the effect of support stiffness in vertical direction under high-speed moving trains. Zeng et al. (2015) investigates the random vibration and the dynamic reliability of train moving over slab track on bridge under track irregularities and earthquakes by the pseudo-excitation method (PEM). A numerical solution for the dynamic response of train-track-bridge coupled system considering the influence of soil-structure interaction (SSI) is studied and verified with the results of field experiments, by Li et al. (2013). Zehsaz et al. (2009) have presented a new method for dynamic analysis for railway, as a beam with limited length, lying on a viscoelastic bed and subjected to moving load is presented. Ülker-Kaustell et al. (2010) has presented a qualitative analysis of the dynamic soil-structure interaction (SSI) of a portal frame railway bridge based on the linear theory of elasticity. Xia et al. (2014) has presented the study of the train-bridge system under collision loads. A continuous bridge with box girders is considered as a case study. A model for dynamic analysis of the vehicle-track nonlinear coupling system is established by the finite element method in Lei et al. (2016). Feenstra and Isenberg (2012) have studied a detailed, three-dimensional finite element model to evaluate the dynamic amplification factor for light rail vehicles.

SAP2000 (2014) is used to analyse the 3D rail bridge. Gharad and Sonparote (2017) have studied and validated the dynamic response of two-dimensional (2D) and threedimensional (3D) bridge models under the action of moving loads, using the same software. Following sections discuss the modelling, analysis and comparison of different loading conditions using the finite element approach.

\section{Modelling of 3D bridge}

The cross-sectional details of a simply supported $26.4 \mathrm{~m}$ span box-girder bridge are shown in Figs. 1 and 2, respectively. Finite element (FE) modelling of the structures (superstructure, piers and substructure) is done in SAP2000 (2014). The material and characteristic values of the railway bridge are shown in Table 1. Table 2 shows the crosssectional properties of the various components of bridge. Figure 3 shows the elevation of Nagpur metro rail bridge. Before modelling, minimum sizes of each section elements were checked as per Indian railway standard-Concrete Bridge Code (CBC 1997). Two different models of the same bridge viz. fixed base model and complete pile model to carry out dynamic analyses are considered. FE model of fixed base box-girder bridge and complete pile model bridge is shown in Figs. 4 and 5, respectively. In complete pile model, the soil layer is simplified as springs based on the Winkler assumption considered by Li et al. (2013). The piles are divided into several uniform sections; then for each section of the pile, two horizontal springs are exerted on middle point of the sections and used to simulate the side thrust of soil, and a vertical spring at the bottom of the pile is used to simulate support reverse force of the rock.

The soil spring stiffness in translational, i.e. $R_{x}, R_{y}$ and $R_{z}$ (stiffness in longitudinal, transverse and vertical) directions and moments $M_{x}$ and $M_{y}$ (rotational stiffness about the longitudinal and transverse axes) mentioned in Table 3 is considered (Xia et al. 2014).

Two horizontal springs with spring constant value of $6000 \mathrm{kN} / \mathrm{m}$ each are assigned on middle point of the sections of pile and a vertical spring at the bottom of the pile with spring constant value calculated as $6000 \mathrm{kN} / \mathrm{m}$ is assigned. These values are evaluated based on IS 2911: 2010.
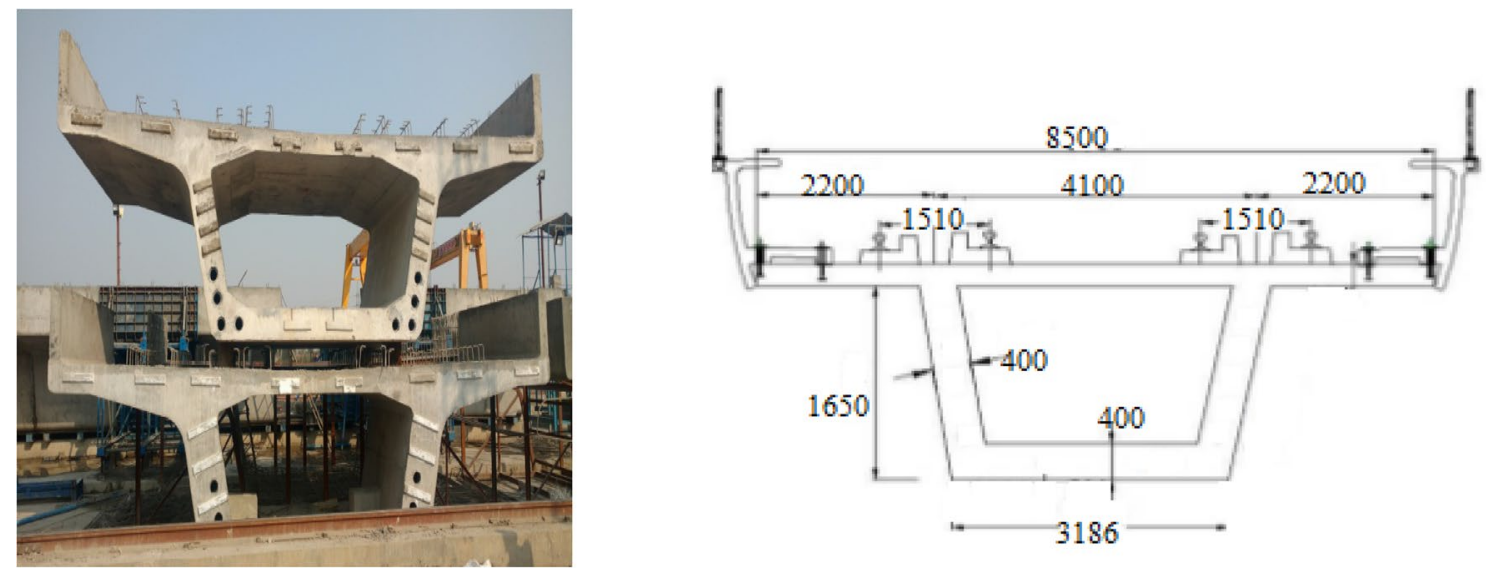

Fig. 1 Sectional view of box-girder (all dimensions are in $\mathrm{mm}$ ) 

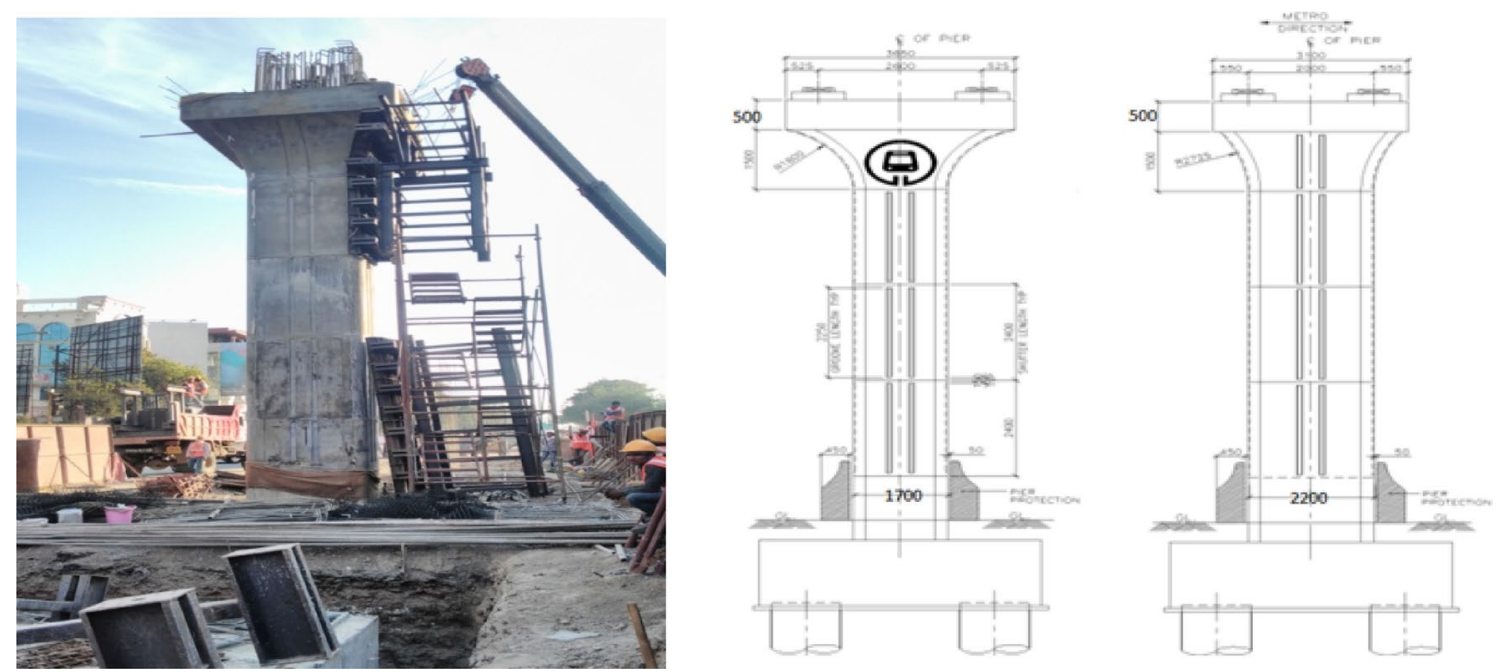

Fig. 2 Elevation of pier, dimensions as per Design basis report (2016) (all dimensions are in mm)

Table 1 Material properties and characteristic values of the railway bridge

\begin{tabular}{llcll}
\hline Properties & $\begin{array}{l}\text { Density }(\mathrm{kN} / \\
\left.\mathrm{m}^{3}\right)\end{array}$ & $\begin{array}{l}\text { Modulus of elasticity } \\
\left(\mathrm{kN} / \mathrm{m}^{2}\right)\end{array}$ & Poisson's ratio & Grade \\
\hline Deck (box-girder) & 25 & $34 \times 10^{6}$ & 0.15 & M50 \\
Pier and pier cap & 25 & $36 \times 10^{6}$ & 0.15 & M60 \\
Pile and pile cap & 25 & $31 \times 10^{6}$ & 0.15 & M40 \\
Rail & 77 & $210 \times 10^{6}$ & 0.30 & 500 \\
Expansion joint filler (Epoxy) & 18 & $6.52 \times 10^{6}$ & 0.35 & - \\
\hline
\end{tabular}

Table 2 Cross-sectional properties of the various components of bridge

\begin{tabular}{llc}
\hline Component & Size $(\mathrm{mm})$ & Depth $(\mathrm{mm})$ \\
\hline Box-girder: & & 1650 \\
Top width & 8500 & \\
Bottom width & 3186 & 500 \\
Pier cap & $3186 \times 2200$ & 11,120 \\
Pier & $1700 \times 2200$ & 1800 \\
Pile cap & $5100 \times 5100$ & 11,800 \\
Pile diameter & 1200 & \\
\hline
\end{tabular}

\section{Rail fastener}

The rails are supported by rail fasteners. The rail fasteners are assigned as links. The stiffness and damping are provided in $\mathrm{U} 1_{(x)}$ longitudinal and $\mathrm{U} 3_{(z)}$ vertical directions. The values of stiffness and damping proposed by Lei et al. (2016), Zeng et al. (2015) and Akogul and Celik (2008) are given in Table 4.

\section{Bearings}

A bridge bearing is a component of a bridge which typically provides a resting surface between bridge piers and the bridge deck. The purpose of a bearing is to allow controlled movement and thereby reduce the stresses involved. Movement could be thermal expansion or contraction, or movement from other sources such as seismic activity. The type of bearing used in the present study is an elastomeric bearing. The bearings are assigned as links and their stiffness and damping values are given in Table 4. Figure 6 represents the considered bearings layout. S1 and S2 indicate hinged support conditions; $\mathrm{B} 1$ indicates bearings allowing the movement in lateral direction and rotation about the transverse direction of deck slab; B2 indicates bearings not allowing any movement but allowing rotation about the transverse direction of deck slab; B3 represents bearings allowing movements in both longitudinal and lateral directions and rotation about the transverse direction of deck slab; and B4 indicates bearings allowing only the longitudinal direction and rotation about the transverse direction of deck slab. 
Fig. 3 Nagpur metro rail bridge elevation

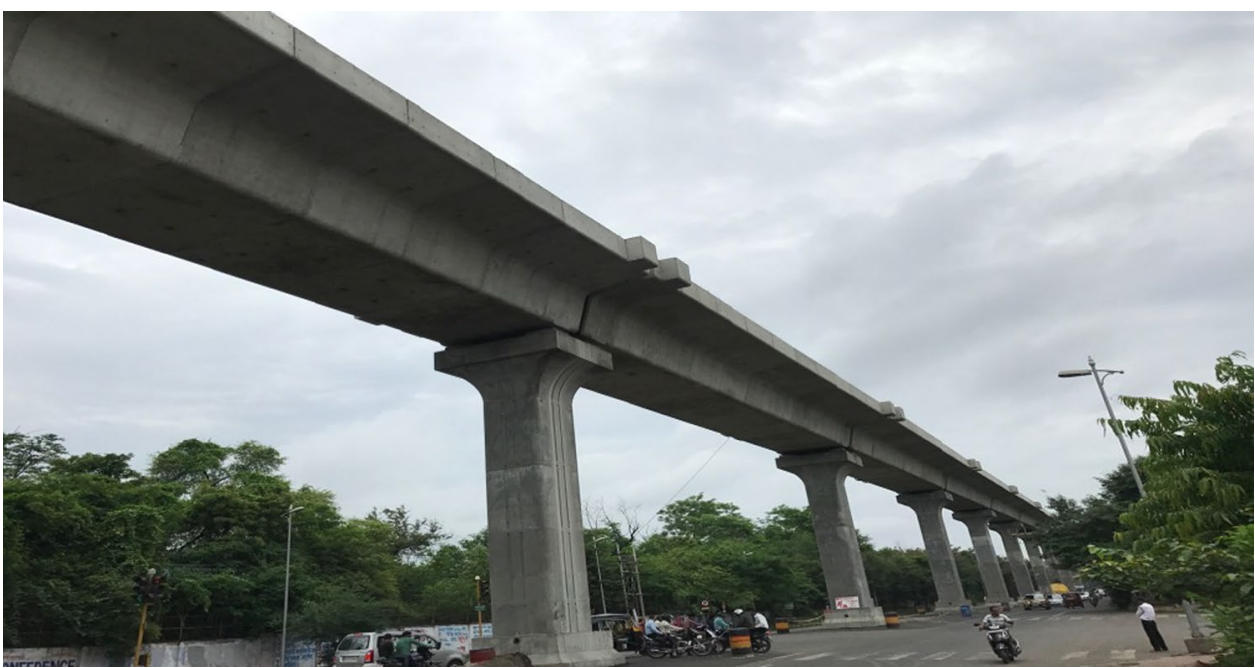

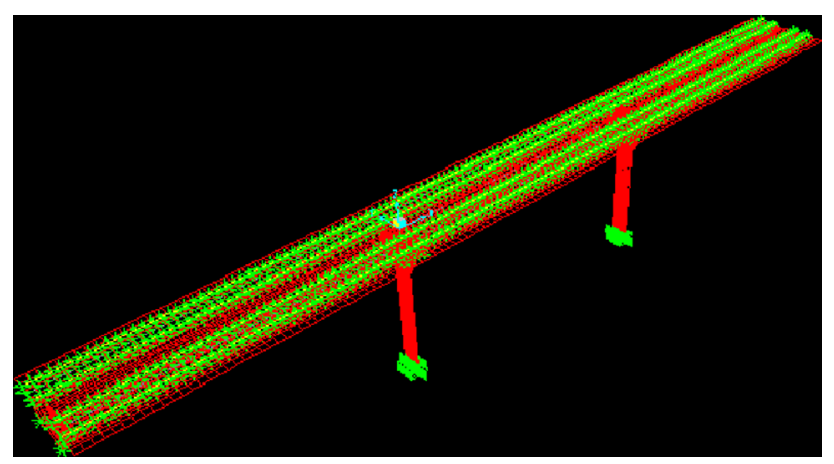

Fig. 4 Geometry of fixed base bridge

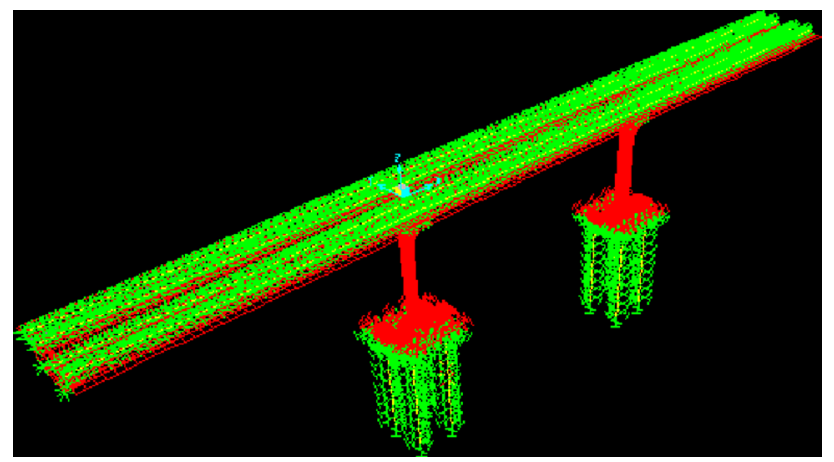

Fig. 5 Geometry of the bridge model with soil-structure interaction (SSI)

Table 3 Foundation stiffness of pile cap

\begin{tabular}{llllll}
\hline $\begin{array}{l}\text { Direc- } \\
\text { tions }\end{array}$ & $\begin{array}{l}R_{z} \\
(\mathrm{MN} / \mathrm{m})\end{array}$ & $\begin{array}{l}R_{x} \\
(\mathrm{MN} / \mathrm{m})\end{array}$ & $\begin{array}{l}M_{y} \\
(\mathrm{MN} \mathrm{m} / \\
\mathrm{rad})\end{array}$ & $\begin{array}{l}R_{y} \\
(\mathrm{MN} / \mathrm{m})\end{array}$ & $\begin{array}{l}M_{x}(\mathrm{MNm} / \\
\mathrm{rad})\end{array}$ \\
\hline Pile cap & $13,328.5$ & 1681.59 & 189,480 & 1681.59 & 189,480 \\
\hline
\end{tabular}

Table 4 Bridge parameters considered in the present study

\begin{tabular}{llr}
\hline Parameters & Unit & \multicolumn{1}{l}{ Value } \\
\hline Rail fastener & & 50,000 \\
Lateral stiffness & $\mathrm{kN} / \mathrm{m}$ & 30,000 \\
Vertical stiffness & $\mathrm{kN} / \mathrm{m}$ & 50 \\
Damping & & $1,143,752$ \\
Bearings & & 80 \\
Stiffness & & $\mathrm{kN} / \mathrm{m}$ \\
Damping & & \\
\hline
\end{tabular}

\section{Moving train load model}

The live load is considered as per NMRCL DBR (2016). The total number of cars in a train is 6 with the length of each car as $21.8 \mathrm{~m}$. Each car consists four axles and load of each axle is same, i.e. $160 \mathrm{kN}$ as shown in Fig. 7. The distance between the axle loads is also given in Fig. 7. The distance of the adjacent bogie is considered as $2.45 \mathrm{~m}$. To calculate the maximum mid-span response of the bridge in vertical direction, moving load analysis is performed for both singleand double track loadings.

\section{Modal and moving load analyses}

To study the dynamic response of a bridge structure, it is essential to carry out modal analysis. The importance of mode shapes has been discussed by Liu et al. (2014). The natural frequency of a system depends only on the stiffness of the structure and the mass which participates with the structure (including self-weight) and is independent of the load function. The information of modal frequencies is necessary to know the resonance phenomenon. This aspect is 
Fig. 6 Layout of bearings on pier

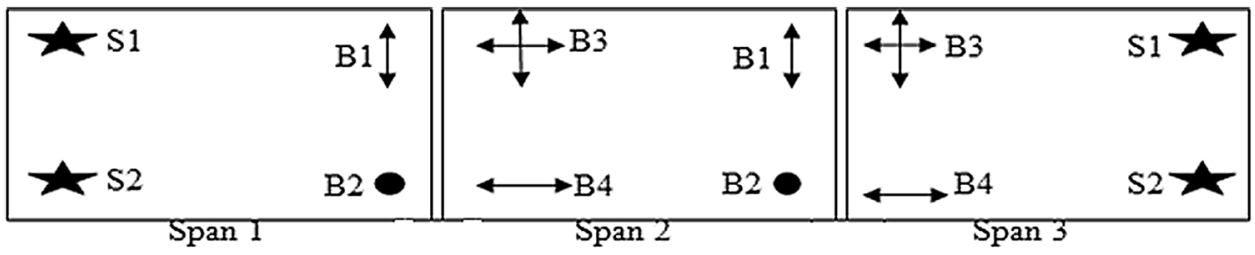

Pier 1
Pier 2

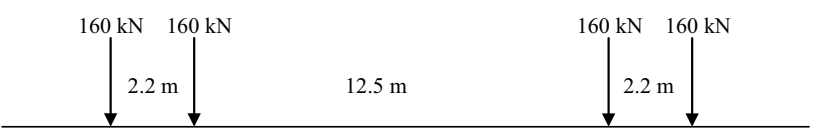

Fig. 7 Standard axle distances of Nagpur metro train

discussed in the subsequent Sect. 4 . Table 5 shows the first four natural frequencies of the bridges as in Figs. 4 and 5 .

The dynamic equations of the bridge system subjected to moving forces can be represented as

$[\mathbf{M}]\left\{\ddot{\mathbf{U}}_{\mathbf{b}}\right\}+[\mathbf{C}]\left\{\dot{\mathbf{U}}_{\mathbf{b}}\right\}+[\mathbf{K}]\left\{\mathbf{U}_{\mathbf{b}}\right\}=\left\{\mathbf{F}_{\mathbf{b}}\right\}$,

where $[\mathbf{M}],[\mathbf{C}],[\mathbf{K}]$, respectively, represent the mass, damping and stiffness of entire bridge system, $\left\{\mathbf{U}_{\mathbf{b}}\right\}$ the bridge displacement, $\left\{\dot{\mathbf{U}}_{\mathbf{b}}\right\}$ the velocity, $\left\{\dot{\mathbf{U}}_{\mathbf{b}}\right\}$ the acceleration and $\left\{\mathbf{F}_{\mathbf{b}}\right\}$ the external moving loads acting on the bridge. Equation (1) is a typical second-order differential equation, which can be solved by number of time-marching schemes. Newmark- $\beta$ method with constants $\beta=1 / 4$ and $\gamma=1 / 2$, is used in this study to determine the dynamic response of the bridge. The solution is obtained using this step-by-step method in the time domain. Eurocode1 (2008) suggests 2\% damping to be adopted for such types of bridges. Since, the design basis report (NMRCL DBR 2016) used the 5\% damping ratio value, thus, in the present study, Rayleigh damping coefficients are evaluated using $5 \%$ modal damping.

\section{Resonant conditions}

The validation of resonant train speed of fixed base model and complete pile model with single train loadings was carried out in vertical direction using formula given by Fryba (2001) and Xia et al. (2014). The maximum vertical acceleration value with respect to vehicle velocities at the midspan of the bridge deck is shown in Table 6. The resonant condition of a bridge excited by a row of moving forces can be expressed by Fryba (2001).

$v_{n, i}=\frac{f_{n} \cdot d}{i} \quad(n=1,2 \ldots i=1,2 \ldots)$,

where $v_{n, i}$ is the resonant train speed, $f_{n}$ is the $n$th resonant frequency of the bridge and $d$ is a characteristic distance

Table 6 Maximum dynamic acceleration in vertical direction with respect to speed for single train loading

\begin{tabular}{lll}
\hline Speed $(\mathrm{km} / \mathrm{h})(v)$ & \multicolumn{2}{l}{ Vertical acceleration $\left(\mathrm{m} / \mathrm{s}^{2}\right)$} \\
\cline { 2 - 3 } & Fixed base model & $\begin{array}{l}\text { Complete } \\
\text { pile model }\end{array}$ \\
\hline 10 & 0.0056 & 0.02655 \\
20 & 0.0106 & 0.02925 \\
30 & 0.0091 & 0.03822 \\
40 & 0.0110 & 0.03798 \\
50 & 0.0119 & 0.0418 \\
60 & 0.0117 & 0.04245 \\
61.30 & 0.01587 & 0.04426 \\
67.08 & 0.01692 & 0.04143 \\
70 & 0.0126 & 0.03881 \\
\hline
\end{tabular}

Table 5 Natural frequencies of the bridge

\begin{tabular}{|c|c|c|c|c|}
\hline \multirow{2}{*}{$\begin{array}{l}\text { Mode num- } \\
\text { ber }\end{array}$} & \multicolumn{2}{|c|}{ Complete pile model } & \multicolumn{2}{|l|}{ Fixed base model } \\
\hline & Frequency $(\mathrm{Hz})$ & Characteristic & Frequency $(\mathrm{Hz})$ & Characteristic \\
\hline 1 & 2.317 & Longitudinal symmetrical floating & 2.535 & Longitudinal symmetrical floating \\
\hline 2 & 2.489 & Lateral symmetrical bending & 2.6222 & Lateral symmetrical bending \\
\hline 3 & 6.256 & $\begin{array}{l}\text { Longitudinal bending with antisymmet- } \\
\text { ric vertical bending }\end{array}$ & 6.292 & $\begin{array}{l}\text { Longitudinal bending with antisym- } \\
\text { metric vertical bending }\end{array}$ \\
\hline 4 & 6.54 & Lateral antisymmetric bending & 6.624 & Lateral antisymmetric bending (twist) \\
\hline
\end{tabular}


between moving loads As per the Wang et al. (2007). The speed limit of Nagpur metro rail is restricted to $70 \mathrm{~km} / \mathrm{h}$. Hence, in the present study, the resonance characteristics of the bridge are evaluated for the speed ranging from 10 to $70 \mathrm{~km} / \mathrm{h}$.

Figure 8 shows the maximum vertical acceleration at the centre of the deck for a range of train speeds between 2.78 and $20.83 \mathrm{~m} / \mathrm{s}$ (10 and $70 \mathrm{~km} / \mathrm{h}$, respectively). The deck acceleration was found to increase with train speed. Local maximum acceleration was reached at resonant speeds corresponding to the first mode shape, considering the characteristic distance $d=14.7 \mathrm{~m}$. Figure 8 shows maximum vibration response at speed $v_{1,2}=67.08 \mathrm{~km} / \mathrm{h}$ represented by the vertical blue line, when soil-bridge interaction was not considered. The response of the structure changed substantially when soil-structure interaction was considered. The second resonant speed of the first mode shape decreased to $v_{1,2}=61.30 \mathrm{~km} / \mathrm{h}$ represented by vertical red line. Both the resonant speeds are evaluated by Eq. (2). In addition, the maximum level of acceleration reached in the resonant regime was significantly lower when the soil-structure interaction was considered. From the above analysis it can be concluded that when the train passes through a multi-span simply supported bridge, the soil-structure interaction has an obvious effect on acceleration of the bridge. The overall stiffness of the bridge becomes smaller when soil-structure interaction is taken into account in the coupled train-track-bridge system, thus, enhancing the vibration response of the bridge and eventually affecting the riding comfort of passengers.

Figure 9 shows the time histories of vertical acceleration at the centre of the mid-span deck for speed (a) $67.08 \mathrm{~km} / \mathrm{h}$ and (b) 61.30. Figure 9a, b shows a gradual increase in the response of the structure with the passage of each bogie. The amplification of the response with each bogie passage was greater when soil-structure interaction was considered.

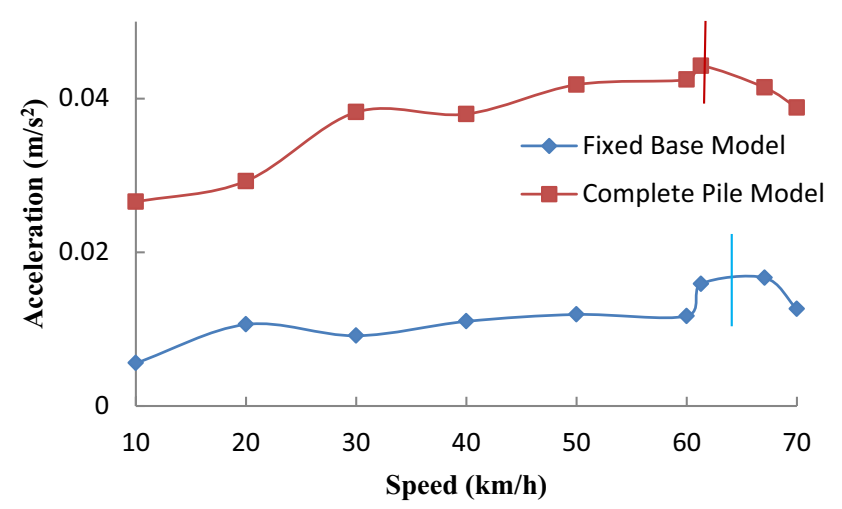

Fig. 8 Variation of maximum vertical acceleration at the centre of the mid-span deck for fixed base model and complete pile model with varying train speeds
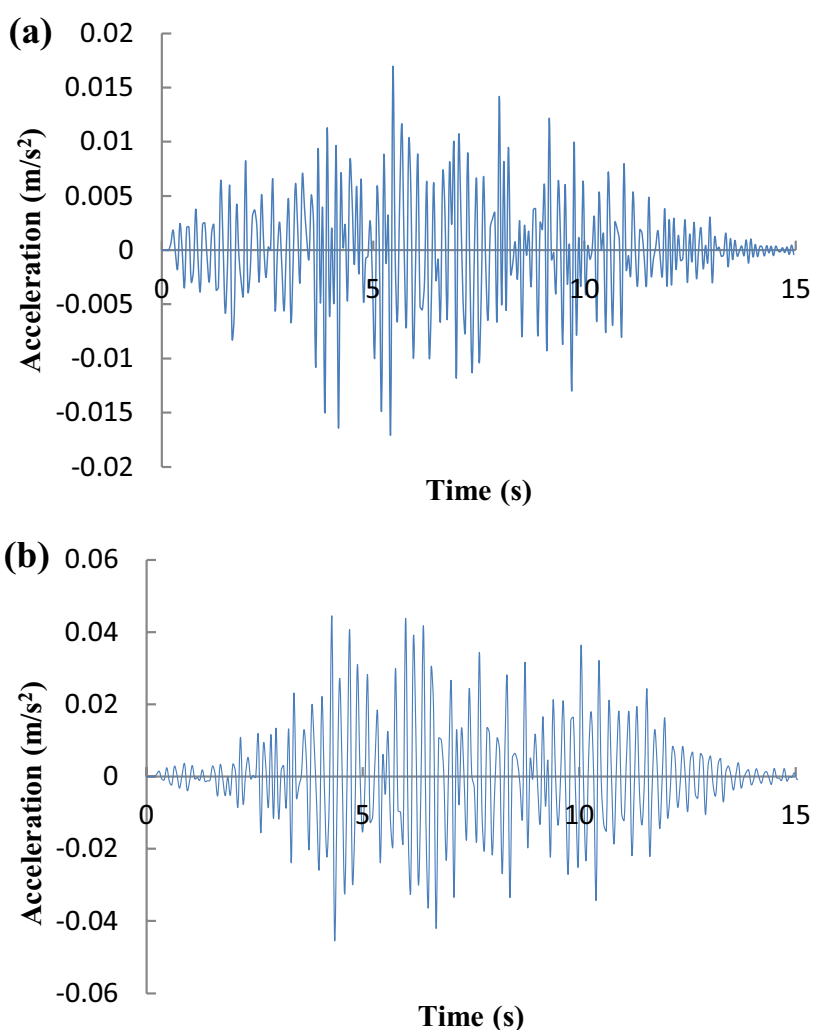

Fig. 9 Time histories of vertical acceleration at the centre of the midspan deck for metro train travelling at a $v=67.08 \mathrm{~km} / \mathrm{h}$ for fixed base model and $\mathbf{b} v=61.30 \mathrm{~km} / \mathrm{h}$ for complete pile model

Figure 10 shows the vertical displacement response at the centre of the mid-span deck of the bridge for fixed base model and complete pile model with varying train speeds. The displacement of the complete pile model is more than the fixed base model. The maximum displacement in both models is obtained at the resonant speed. The displacement response for the fixed base model shows steady response

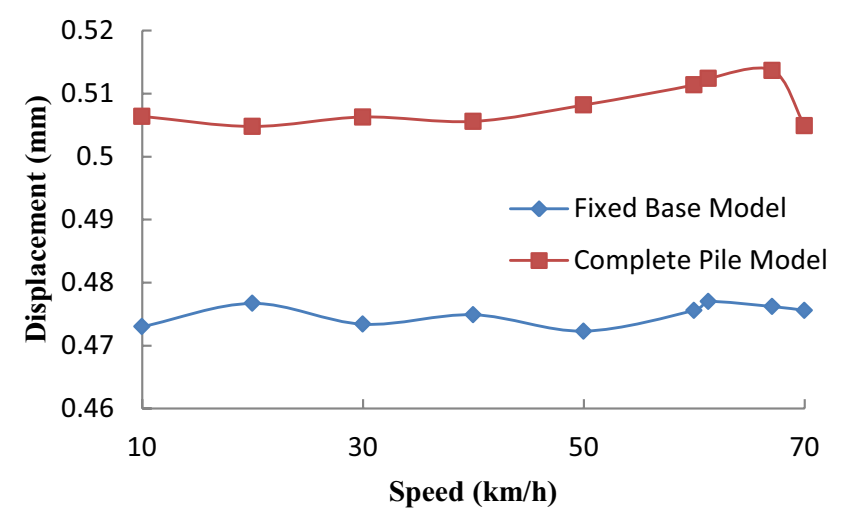

Fig. 10 Variation of maximum vertical displacement at the centre of the mid-span deck for fixed base model and complete pile model with varying train speeds 
and lower values compared to the complete pile model due to infinite stiffness offered at the base.

Figure 11 shows the time history plots of the vertical displacements at resonance for the fixed base and complete pile models.

\section{Double train loadings}

In this section, FE analysis of the aforementioned bridge subjected to train loads ("Moving train load model") moving in opposite directions on the two tracks is discussed. These trains are assumed to enter the tracks at the same instant. Two models viz. the fixed base and complete pile are again considered. Variation of maximum dynamic acceleration and displacement response in the vertical direction with respect to the speed for double train loadings are shown in Fig. 12.

Figure 12a shows the maximum vertical acceleration at the centre of the mid-span deck. The acceleration response of bridge increases with the growth of train speed. In this case, the resonance for complete pile model and for fixed base model is achieved at $60 \mathrm{~km} / \mathrm{h}$. From Fig. 12b, it is clear that the displacement response of the complete pile model is more than the fixed base model. Figures 13 and 14 show the

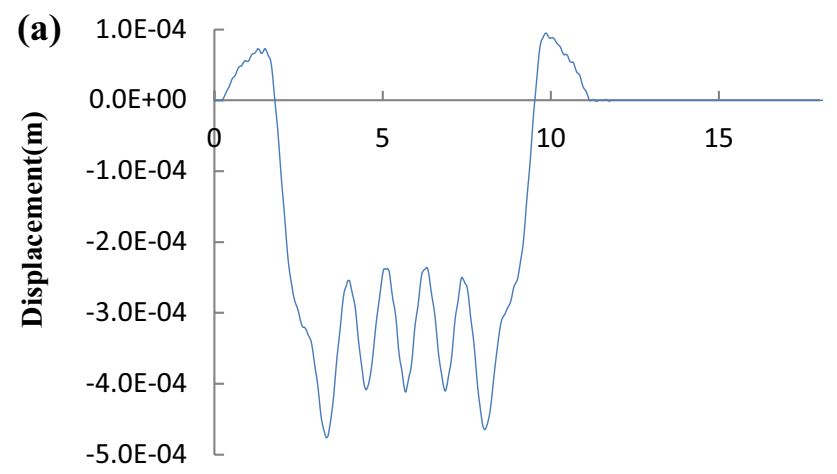

Time (s)

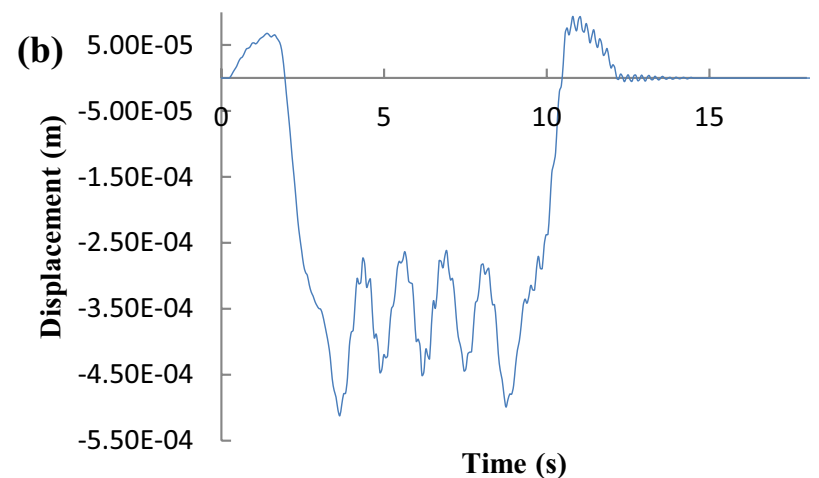

Fig. 11 Time histories of vertical displacement at the centre of the mid-span deck for metro train travelling at a fixed base model for $v=67.08 \mathrm{~km} / \mathrm{h}$ and $\mathbf{b}$ complete pile model $v=61.30 \mathrm{~km} / \mathrm{h}$
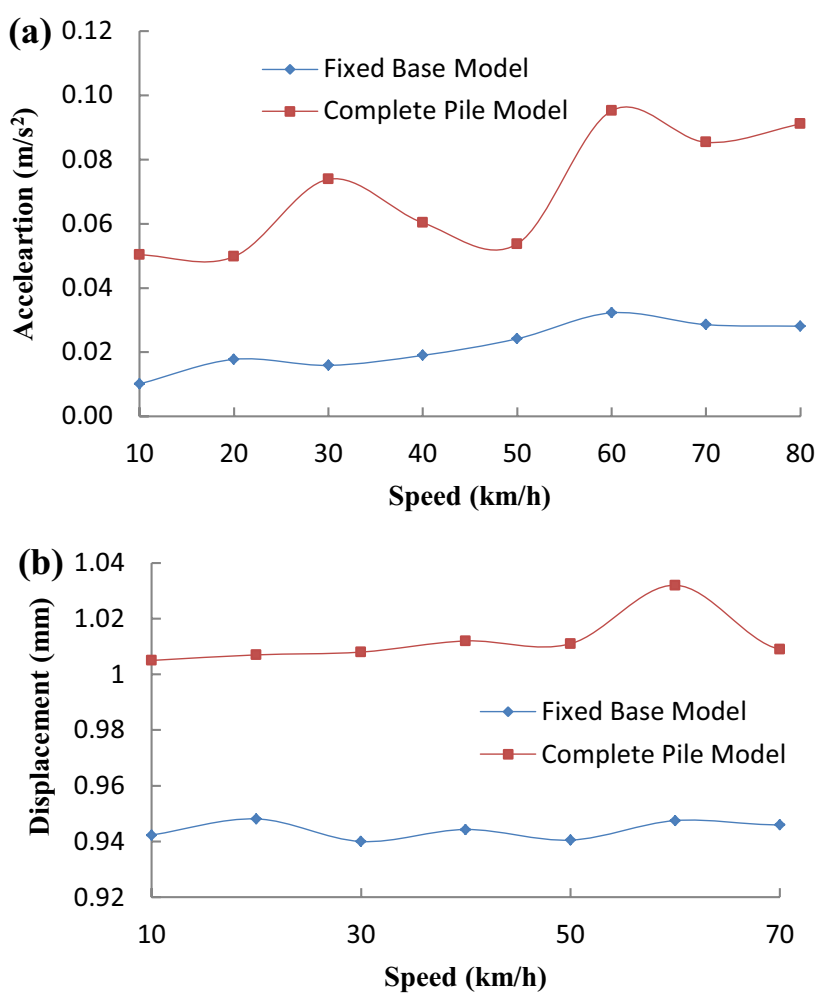

Fig. 12 Variation of maximum vertical $\mathbf{a}$ acceleration and $\mathbf{b}$ displacement vs. speed

time histories of vertical accelerations and displacements, respectively, for both the bridge models at the resonant speed of $60 \mathrm{~km} / \mathrm{h}$. It is interesting to note that for this case, the vertical resonant speed is obtained from Fig. 12, since, Eq. (2) is not sufficient to identify the resonant speed.

\section{Comparative studies}

In the previous sections, the maximum acceleration and displacement responses at the centre of the mid-span deck due to single train and double train loadings were calculated. In this section, a comparison of the dynamic responses, obtained due to these load cases, for the two different bridge models (fixed base and complete pile) is done.

\section{Fixed base model}

For the fixed base model, the acceleration and displacement responses with varying train speeds for both the loading cases viz. single train and double train (moving in opposite directions) are shown in Fig. 15. From Fig. 15a, it is verified that the acceleration response of both the single and double train loading increases with the train speed. Nevertheless, an obvious increase in the acceleration values for the double 

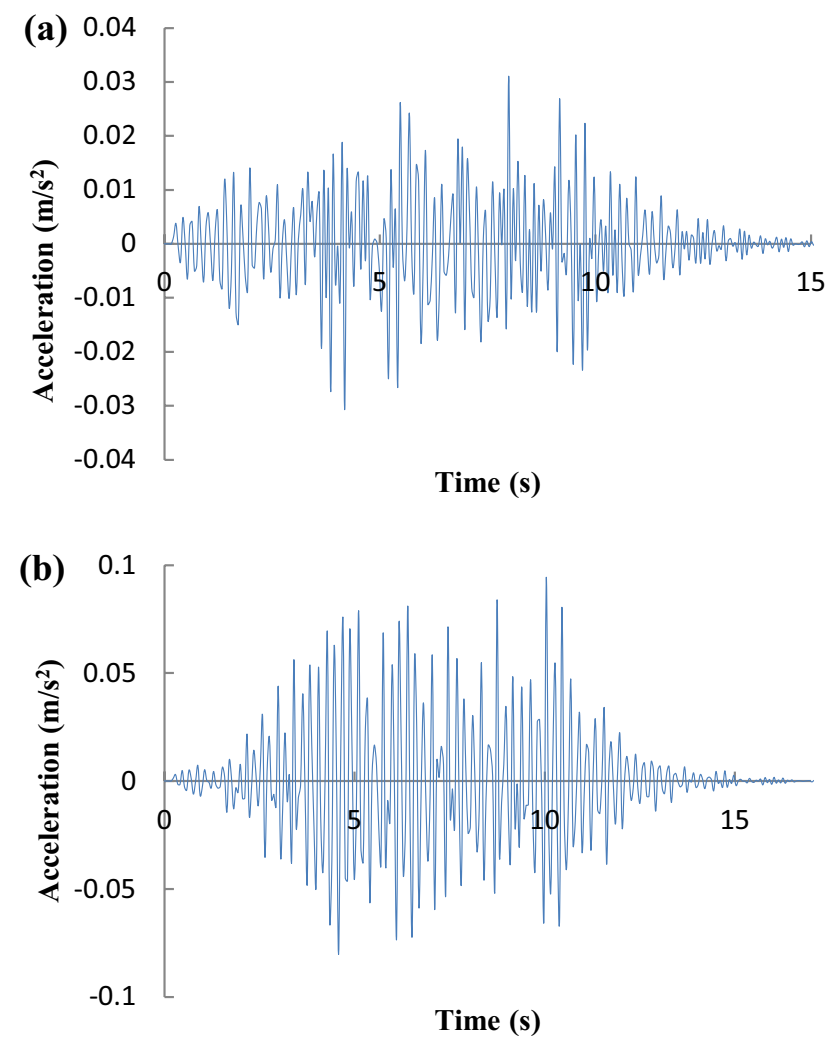

Fig. 13 Time histories of vertical acceleration at the centre of the mid-span deck for metro train travelling at $v=60 \mathrm{~km} / \mathrm{h}$ on a fixed base model and $\mathbf{b}$ complete pile model

train loading case compared to the single train loading case with the varying train speeds is observed. The nature of the displacement responses (excluding their magnitudes) for both the loading cases with varying train speeds is same (Fig. 15b).

\section{Complete pile model}

For the complete pile model, the acceleration and displacement responses with varying train speeds for both the loading cases viz. single train and double train (moving in opposite directions) are shown in Fig. 16. From Fig. 16a, it is verified that the acceleration response of both the single and double train loading increases with the train speed. Nevertheless, an obvious increase in the acceleration values for the double train loading case compared to the single train loading case with the varying train speeds is observed. The nature of the displacement responses (excluding their magnitudes) for both the loading cases with varying train speeds is same (Fig. 16b).

From the above comparison, it can be stated that for the double train loading case, a definite increase in the acceleration and displacement values compared to the single train loading case is evident. Thus, during dynamic analysis of
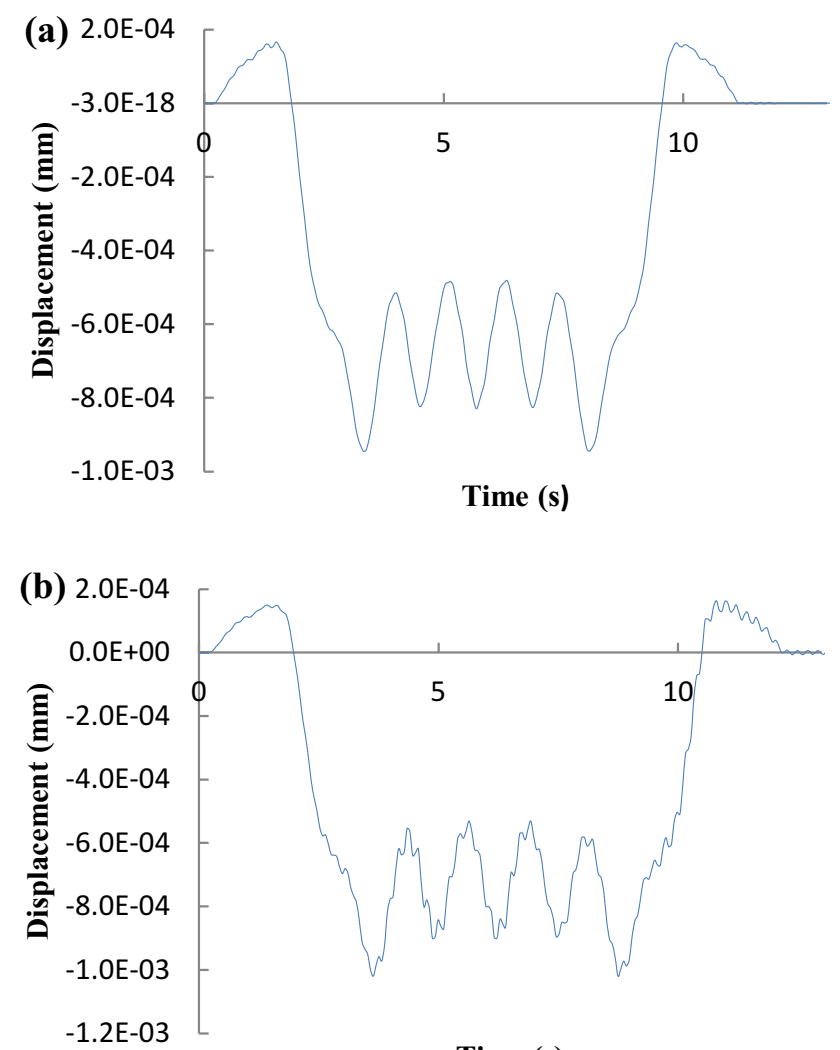

Time (s)

Fig. 14 Time histories of vertical displacement at the centre of the mid-span deck for metro train travelling at $v=60 \mathrm{~km} / \mathrm{h}$ on a fixed base $\mathbf{b}$ complete pile

such bridges, the contribution of various loading conditions, developing the critical vertical bridge deck responses, should be considered.

\section{Limits for displacement}

The excessive bridge deformations can endanger traffic by causing unacceptable changes in geometry of the track and in bridge structures, which leads to discomfort of passengers. The UIC-code (International Union of railways) 776-3 $\mathrm{R}$ (1989) recommends the limitations to be placed on bridge deformation to avoid risk to traffic and discomfort to passengers. The vertical deflection for the considered bridge, due to live load is obtained as $1.03 \mathrm{~mm}$, which is within the limits specified in the code.

\section{Conclusions}

In this study, finite element method to model and analyse a 3D metro rail bridge subjected to concentrated moving loads is considered. Due to the availability of various modelling 

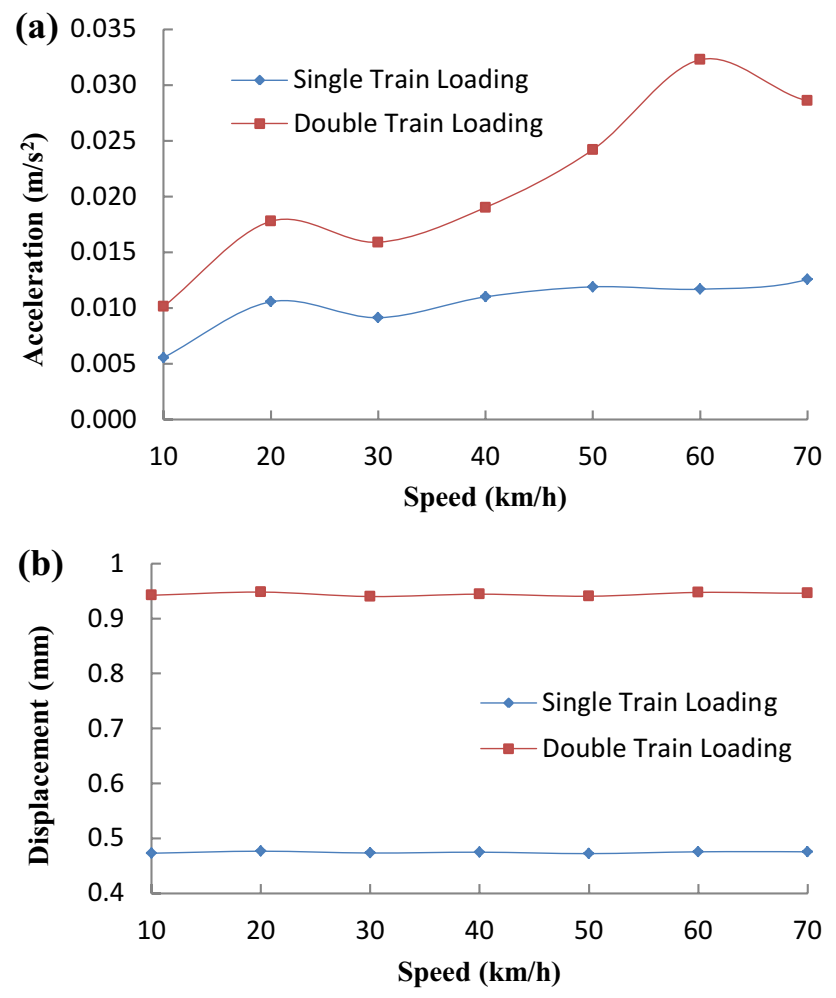

Fig. 15 Variation of maximum vertical a acceleration $\mathbf{b}$ displacement vs. speed

and computational techniques, an attempt should be done to model a given complex structure very close to a real structure. Hence, considering this aspect, the 3D model was prepared and analysed for the given loads. The 3D model consists of bridge deck, piers, foundation including piles and soil springs attached to the foundations and piles to consider the effects of soil-structure interaction. To study the behaviour of the bridge under dynamic loading, two different models subjected to two different loading conditions are analysed. From this comparative study, following conclusions can be drawn.

1. The natural frequency of a multi-span simply supported bridge plays a vital role in identifying its vertical resonance response. The maximum vertical resonant speed of the bridge deck (under single train loading) corresponds to the fundamental frequency of the bridge structure.

2. The dynamic behaviour of the bridge structure is governed by the soil-bridge interaction under moving loads. The vertical acceleration response of the mid span of bridge deck is obtained at lower speeds under moving loads when SSI is considered for both the loading conditions. The fixed base model does not represent the actual dynamic behaviour of the bridge structure. Hence,
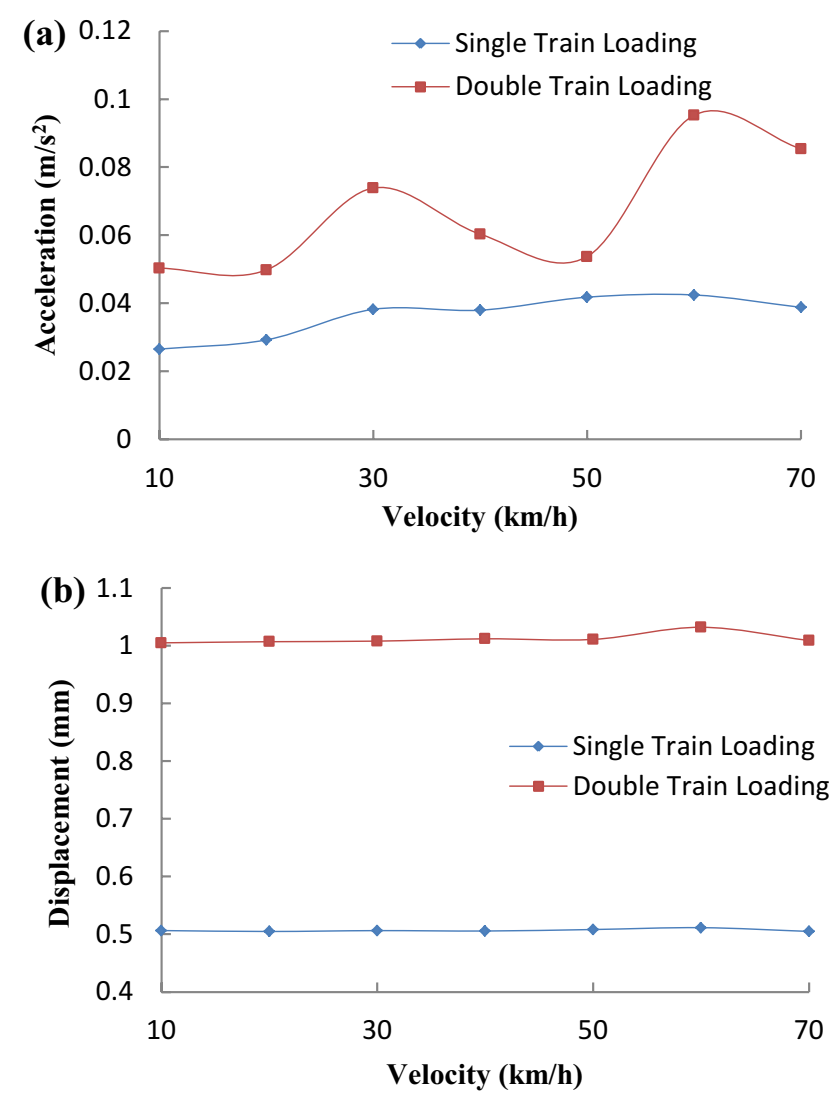

Fig. 16 Variation of maximum vertical $\mathbf{a}$ acceleration and $\mathbf{b}$ displacement vs. speed

it becomes a prime responsibility to analyse any given structure under dynamic loading considering SSI.

3. For the case when two trains were assumed to be moving in opposite directions, a definite increase in the acceleration and displacement values compared to the single train loading case was observed. Thus, during dynamic analysis of such bridges, the contribution of various loading conditions, developing the critical vertical bridge deck responses, should be considered.

4. The vertical deformations caused due to live loads, for this particular bridge, are within safety allowances as per the guidelines of UIC code.

Acknowledgements The authors are thankful to Nagpur Metro Rail Corporation Limited, Nagpur and special thanks to Dr. M. P. Ramnavas, General Manager/Design, Nagpur Metro Rail Corporation Limited, Nagpur, for providing the necessary information. The authors are also thankful to the anonymous reviewers for their essential suggestions.

Open Access This article is distributed under the terms of the Creative Commons Attribution 4.0 International License (http://creativeco mmons.org/licenses/by/4.0/), which permits unrestricted use, distribution, and reproduction in any medium, provided you give appropriate 
credit to the original author(s) and the source, provide a link to the Creative Commons license, and indicate if changes were made.

\section{References}

Akogul C, Celik OC (2008) Effect of elastomeric bearing modelling parameters on the seismic design of $\mathrm{RC}$ highway bridges with precast concrete girders. In: The 14th world conference on earthquake engineering, Beijing, China

Design basis report (2016) Nagpur metro rail project. Nagpur Metro Rail Corporation Limited, Nagpur

European Committee for Standardisation (CEN) (2008) Eurocode1: actions on structures-part 2: traffic loads on bridges

Feenstra P, Isenberg J (2012) Dynamic amplification factor for light rail vehicle transiting box-girder bridge. Struct Congr (ASCE). https ://doi.org/10.1061/9780784412367.036

Fryba L (2001) A rough assessment of railway bridges for high speed trains. Eng Struct 23:548-556

Gharad AM, Sonparote RS (2017) Assessment of resonance effects on railway bridges under moving loads. J Struct Eng 5(4):38

Indian railway standard (1997) Code of practice for plain, reinforced $\&$ prestressed concrete for general bridge construction. Concrete Bridge Code, Lucknow

IS 2911 (Part 1, Sec 2) (2010) Design and construction of pile foundations - code of practice. Bureau of Indian Standards, New Delhi

Ju SH, Lin HT (2003) Resonance characteristics of high-speed trains passing simply supported bridges. J Sound Vib 267:1127-1141

Lei X, Wu S, Zhang B (2016) Dynamic analysis of the high speed train and slab track nonlinear coupling system with the cross iteration algorithm. J Nonlinear Dyn 2016:1-17

Li XZ, Liu XH, Liu DJ, Zhang X (2013) Influences of soil-structure interaction on coupled vibration of train-bridge system: theoretical and experimental study. Adv Struct Eng 16(8):1355-1364

Liu K, Lombaert G, Roeck GD (2014) Dynamic analysis of multispan viaducts with weak coupling between adjacent spans. J Bridge Eng ASCE 19(1):83-90
Romero A, Solis M, Dominguez J, Galvin P (2013) Soil-structure interaction in resonant railway bridges. Soil Dyn Earthq Eng 47:108-116

Salcher P, Adam C (2012) Simplified assessment of high-speed train induced bridge vibrations considering shear effects. Proc Appl Math Mech 12:197-198

SAP2000 v14.2.4 (2014) Integrated software for structural analysis \& design. User's manual. http://www.csiberkeley.com/produ cts_SAP.html

Tavares RA (2007) Influence of the vertical support stiffness on the dynamic behavior of high-speed railway bridges. Master thesis, Royal Institute of Technology (KTH), Sweden

UIC Code, International Union of Railways 776-3R (1989) Deformation of bridges, 1st edn. International Union of Railways

Ülker-Kaustell M, Karoumia R, Pacoste C (2010) Simplified analysis of the dynamic soil-structure interaction of a portal frame railway bridge. Eng Struct 32:3692-3698

Wang Y, Weia QC, Shia J, Longa X (2007) Resonance characteristics of two-span continuous beam under moving high speed trains. Lat Am J Solids Struct 7:185-199

Xia CY, Xia H, Roeck GD (2014) Dynamic response of a train-bridge system under collision loads and running safety evaluation of high-speed trains. Comput Struct 140:23-38

Zehsaz M, Sadeghi MH, Asl Z (2009) Dynamics response of railway under a moving load. J Appl Sci 9(8):1474-1481

Zeng ZP, Zhao YG, Xu WT, Yu ZW, Chen LK, Lou P (2015) Random vibration analysis of train-bridge under track irregularities and traveling seismic waves using train-slab track-bridge interaction model. J Sound Vib 342:22-43

Zhang N, Xia H, Roeck GD (2010) Dynamic analysis of a train-bridge system under multi-support seismic excitations. J Mech Sci Technol 24(11):2181-2188

Publisher's Note Springer Nature remains neutral with regard to jurisdictional claims in published maps and institutional affiliations. 